\title{
ARBORIZAÇÃO URBANA NO MUNICÍPIO DE TRÊS RIOS-RJ: ESPÉCIES UTILIZADAS E A PERCEPÇÃO DE SEUS BENEFÍCIOS PELA POPULAÇÃO
}

\author{
Débora Chaves Faria $^{12}$; Júlia Maria de Aguiar Duarte ${ }^{3}$; Daniel Marques Pinto ${ }^{3}$ \& Fábio Souto Almeida ${ }^{4}$
}

\section{RESUMO}

Objetivou-se estudar a arborização urbana no Município de Três Rios-RJ e analisar a percepção da população sobre os benefícios e malefícios da presença das árvores no meio urbano. Foi realizado o levantamento da arborização nos bairros Centro e Vila Isabel. Para avaliar a percepção da população sobre a arborização urbana, foram aplicados 100 questionários aos moradores de cada bairro. Foram encontradas 139 plantas no Centro $(0,61$ árvores/ $10 \mathrm{~m}$ de calçada), pertencentes a 25 espécies. Na Vila Isabel foram encontradas 9 árvores (0,05 árvores/ $10 \mathrm{~m}$ de calçada), pertencentes a 7 espécies. A porcentagem de árvores em conflito com a rede aérea foi de $69,32 \%$ e a porcentagem de árvores causando danos às calçadas foi de $62,00 \%$. Dentre as espécies amostradas, as mais promissoras para uso na arborização urbana, buscando minimizar os danos a calçadas e à rede aérea de transmissão de energia elétrica e telefonia, são Bauhinia aff. purpurea L., Cassia fistula L., Nerium oleander L. e Licania tomentosa (Benth.) Fritsch. O Centro é mais arborizado que a Vila Isabel, o que se reflete na avaliação realizada pelos moradores dos dois bairros. Os moradores do Centro se mostraram mais satisfeitos com a arborização do seu bairro que os moradores da Vila Isabel.

Palavras-chave: áreas verdes; clima urbano; conforto térmico; espécies arbóreas.

\section{URBAN FORESTRY IN TRÊS RIOS, RIO DE JANEIRO STATE, BRAZIL: SPECIES AND THE PERCEPTION OF PEOPLE ON BENEFITS}

\begin{abstract}
This study aimed to evaluate the urban forestry in Três Rios, Rio de Janeiro State, Brazil, and to analyze the population's perception about the benefits and disadvantages of the trees in urban areas. We conducted a census of trees in the Centro and Vila Isabel neighborhoods. To assess the population's perception about the urban forestry, 100 questionnaires were applied to residents of each neighborhood. In the Centro, we have found 139 plants (0,61 trees/ $10 \mathrm{~m}$ of sidewalks) and 25 species. In the Vila Isabel, were found 9 trees $(0,05$ trees/ $10 \mathrm{~m}$ of sidewalks) and 7 species. The percentage of trees in conflict with the transmission line of electricity and the telephone cables was $69.32 \%$ and the percentage of trees causing damage to sidewalks was $62.00 \%$. Among the species sampled, the most promising for use in sidewalks, minimizing damage to sidewalks and damage to transmission line of electricity and the telephone cables, are Bauhinia aff. purpurea L., Cassia fistula L., Nerium oleander L. and Licania tomentosa (Benth.) Fritsch. The Centro has more trees than the Vila Isabel. The residents of the Centro are more satisfied with the benefits of the urban forestry in your neighborhood that the residents of the Vila Isabel.
\end{abstract}

Key-words: green areas; thermal comfort; tree species; urban climate.

\footnotetext{
${ }^{1}$ recebido em 20.04.2013 e aceito para publicação em 15.06.2013

${ }^{2}$ Bolsista de Apoio Técnico-Acadêmico, Discente do Curso de Gestão Ambiental, UFRRJ, Três Rios-RJ, debora niksa@hotmail.com

${ }_{3}^{3}$ Discentes do Curso de Gestão Ambiental, UFRRJ,Três Rios-RJ, julia.m.a.duarte@gmail.com,daniel_marques_pinto@yahoo.com.br

${ }^{4}$ Departamento de Ciências Administrativas e do Ambiente, UFRRJ, Três Rios-RJ, fbio_almeida@yahoo.com.br
} 
A urbanização ocasiona diversos problemas ambientais, incluindo modificações adversas no microclima e na paisagem, que afetam a qualidade de vida e a saúde da população. A arborização das vias públicas é uma estratégia utilizada para minimizar tais problemas (FARIA et al., 2007). Os benefícios que a arborização urbana proporciona incluem a melhoria do microclima e a ação contra a poluição acústica e atmosférica (COLTRO; MIRANDA, 2007; FERNANDES, 2007; SMITH, 1977). Proporciona também melhorias estéticas ao ambiente urbano (EMBRAPA, 2009; SANTOS; TEIXEIRA, 2001). Assim, oferece benefícios para a saúde do homem e proporciona a melhoria da qualidade de vida. A arborização urbana também desempenha uma função ecológica, pois contribui para a conservação de parte da biodiversidade regional, fornecendo abrigo e alimentação para espécies de animais (BLUM et al., 2008). Conhecer a composição da arborização das vias públicas é de fundamental importância para o planejamento e a administração das áreas urbanas, objetivando o bem estar da população e salvaguardar a diversidade biológica local (KURIHARA et al., 2005; ROCHA et al., 2004; TEIXEIRA, 1999).

Ao se planejar a arborização urbana deve-se atentar para uma série de questões, incluindo a escolha das espécies que melhor se adaptam ao local de plantio, analisando o seu crescimento, a forma do tronco, o tipo de fruto e a forma da copa (PAIVA, 2000). Além disso, deve-se buscar informações sobre o estado atual das árvores já existentes, o que contribui para o planejamento eficaz da sua manutenção (DANTAS; SOUZA, 2004). É necessário coletar informações sobre a composição de espécies, a altura das árvores e o diâmetro das copas (KURIHARA et al., 2005; ROCHA et al., 2004; TEIXEIRA, 1999).

Diversos problemas podem surgir da falta de planejamento e de cuidados com as árvores, como a não realização da poda periódica (COLTRO; MIRANDA, 2007; SPADOTTO; DELMANTO JÚNIOR, 2009). Entre tais problemas, pode-se citar os conflitos com a rede de transmissão de energia elétrica ou com a rede de telefonia, que evidenciam a necessidade de poda ou a escolha equivocada da espécie de árvore (ROCHA et al., 2004). Outro sério problema são os danos causados às calçadas públicas pelas raízes das árvores (SPADOTTO; DELMANTO JÚNIOR, 2009). Cabe ressaltar que a alocação e a forma das estruturas do meio urbano, como os postes de iluminação pública e a rede aérea de transmissão de energia elétrica e de telefonia, necessárias para as atividades do ser humano no meio urbano, muitas vezes não são planejadas para conviver de forma harmônica com as árvores (RIBEIRO, 2009).

O Município de Três Rios-RJ está em rápido processo de desenvolvimento. O planejamento do crescimento das áreas urbanas e a sua administração eficaz são necessários para que o desenvolvimento do município seja ordenado, possibilitando a existência de um meio ambiente que ofereça uma boa qualidade de vida para a população. Assim, informações que possam contribuir para o planejamento e a manutenção da arborização das vias públicas são de elevada importância. Nesse sentido, a avaliação da percepção da população sobre a arborização urbana pode ser uma fonte de informações importante para aprimorar os benefícios oriundos da presença das

ARBORIZAÇÃo URBANA NO MUNICÍPIO DE TRÊS RIOS-RJ... 
plantas e minimizar os possíveis problemas causados pelas mesmas.

O objetivo do trabalho foi estudar a arborização urbana no Município de Três Rios e analisar a percepção da população sobre a arborização. Buscou-se identificar as espécies de árvores que causam menos danos à rede aérea de transmissão de energia elétrica, à rede aérea de telefonia e às calçadas públicas. Além disso, a arborização das vias públicas de dois bairros do município foi comparada e foi verificada a percepção da população sobre a arborização nesses dois bairros.

\section{MATERIAIS E MÉTODOS}

O estudo foi realizado no município de Três Rios (226'58"S; 4312'23"O), que está situado na mesorregião Centro-Sul Fluminense, Estado do Rio de Janeiro. O município apresenta uma população de 77.432 habitantes, área de 326,136 km² e altitude média de 269 m (IBGE, 2012). A temperatura varia de $14,2{ }^{\circ} \mathrm{C}$ a $37,4{ }^{\circ} \mathrm{C}$ e a precipitação anual média é aproximadamente de $1.300 \mathrm{~mm}$.

Foi realizado o censo da arborização de três ruas dos bairros Centro e Vila Isabel. No Centro inventariou-se a Rua 14 de Dezembro, a Rua Oswaldo Cruz e a Rua Barbosa de Andrade, totalizando $2.272 \mathrm{~m}$ de calcadas. Na Vila Isabel as ruas inventariadas foram a Rua Anibal Peixoto Lavinas, a Rua Lincol de Almeida e a Rua Joaquim Gomes Veiga, somando $1.975 \mathrm{~m}$ de calçadas. O Bairro Centro é uma área residencial considerada nobre no município e apresenta elevada quantidade de estabelecimentos comerciais. O Bairro Vila Isabel é o bairro mais populoso da cidade, com um comércio relativamente pequeno, ainda em expansão. Nesse bairro está a maioria dos novos empreendimentos imobiliários.

O levantamento da arborização foi realizado no período de novembro de 2010 a abril de 2011. Foram obtidos, para cada árvore, a altura total e o diâmetro da copa (sentido longitudinal e transversal ao meio fio). Sempre que possível, procedeu-se a identificação das espécies. Ao se observar a presença de rede aérea de transmissão de energia elétrica ou de telefonia, verificava-se a existência de conflitos entre as árvores e a rede aérea. Além disso, foi verificado se as plantas estavam causando danos às calçadas. Foi realizado o cálculo da frequência relativa de cada espécie e o número de plantas por $10 \mathrm{~m}$ de calçada, em cada bairro (ROCHA et al., 2004). Também foi calculada a porcentagem de árvores que estavam em conflito com a rede aérea ou causavam danos às calçadas. Todavia, para o cálculo da porcentagem de indivíduos em conflito com a rede aérea foram utilizadas somente as plantas que estavam em locais onde havia rede aérea de transmissão de energia elétrica ou de telefonia.

Para avaliar a percepção da população sobre a arborização urbana, foram aplicados 100 questionários aos moradores de cada bairro, nos meses de julho e agosto de 2012. Os questionários utilizados foram baseados no trabalho de COLTRO \& MIRANDA (2007). Foi obtido o grau de satisfação da população quanto à arborização, a opinião dos moradores sobre a qualidade da arborização e os benefícios estéticos, benefícios psicológicos e benefícios quanto ao clima. No questionário foi perguntado qual é o benefício mais importante e quais são os aspectos negativos da arborização urbana. Foi utilizado o teste de Qui-

Débora Chaves Faria et al. 
Foram encontradas 139 plantas no bairro Centro (0,61 árvores/ $10 \mathrm{~m}$ de calçada), pertencentes a 25 espécies (Tab. 1). As cinco espécies mais frequentes no bairro representam mais de $69 \%$ do total de árvores. As espécies mais frequentes, como Cassia siamea Lam. (cássia siamea), Licania tomentosa (Benth.) Fritsch. (oiti), Pachira aquatica Aubl. (munguba) e Terminalia catappa L. (amendoeira), são amplamente utilizadas na arborização de vias públicas no Brasil (PEREIRA et al., 2010; ROCHA et al., 2004). Já na Vila Isabel, foram encontradas apenas 9 árvores (0,05 árvores/ $10 \mathrm{~m}$ de calçada), pertencentes a 7 espécies. Observa-se então uma expressiva diferença na arborização dos dois bairros, evidenciando a falta de planejamento urbano e de preocupação com a arborização no bairro Vila Isabel.

No geral, a porcentagem de árvores em conflito com a rede aérea de transmissão de energia elétrica e de telefonia foi de $69,32 \%$ e a porcentagem de árvores causando danos às calçadas foi de $62,00 \%$. Isso indica que ocorreram erros na escolha das espécies utilizadas ou na manutenção das árvores (MILANO, 1987). Além disso, a forma de plantio pode não ter sido a ideal, pois existem técnicas para evitar os danos às calçadas (PIVETTA; SILVA FILHO, 2002). No bairro Centro, a porcentagem de árvores em conflito com a rede aérea de transmissão de energia elétrica ou de telefonia foi de 71,95\% e a porcentagem de árvores causando danos às calçadas foi de 64,50\%. Na Vila Isabel a porcentagem de árvores em conflito com a rede aérea e causando danos às calçadas foi de 33,33\%. Entretanto, na Vila Isabel o baixo número de árvores não possibilita uma análise mais profunda da questão. Além disso, alguns indivíduos amostrados no bairro eram jovens.

Dentre as espécies mais frequentes, C. siamea, $P$. aquatica e T. catappa apresentaram elevada porcentagem de indivíduos em conflito com a rede aérea de transmissão de energia elétrica ou de telefonia (Tab. 1). Entretanto, L. tomentosa, Bauhinia aff. purpurea L. (pata-de-vaca) e Cassia fistula L. (chuva-de-ouro) apresentaram uma porcentagem menor, em relação às citadas anteriormente, de indivíduos em conflito com a rede aérea. Já Nerium oleander L. (espirradeira) não apresentou indivíduos em conflito com a rede aérea. Logicamente, a porcentagem de indivíduos em conflito com a rede aérea de transmissão de energia elétrica ou de telefonia está relacionada à altura das árvores, como observado por BOHNER et al. (2011). Como os indivíduos de $N$. oleander possuíam altura inferior a da rede área, não entraram em conflito com a mesma. Além da altura, o diâmetro da copa é importante, como evidenciado no presente trabalho. Para evitar os danos à rede aérea de transmissão de energia elétrica ou de telefonia, além da escolha das espécies de árvores mais adequadas para cada situação, deve-se realizar a poda periodicamente (VELASCO, 2003). Quanto aos danos às calçadas, dentre as espécies de árvores mais frequentes nas ruas do município, C. siamea, $P$. aquatica e T. catappa também foram as espécies com maior frequência de indivíduos causando danos. O oiti, a pata-de-vaca e a chuva-de-ouro apresentaram porcentagem de indivíduos causando danos às calçadas expressivamente inferiores às das espécies citadas acima. No geral, pode-se observar que não foram tomados os devidos cuidados para se 
evitar os danos às calçadas, pois esses podem ser minimizados com a escolha correta das espécies, dando preferência para espécies com sistema radicular que se desenvolva pouco próximo à superfície (GRACIOLI et al., 2011), e com técnicas de plantio adequadas, como revestir parte da cova com concreto para direcionar o crescimento das raízes (PIVETTA; SILVA FILHO, 2002).

A espirradeira é uma planta paisagística, porém se o objetivo for obter sombra e amenizar o calor, a espécie não parece adequada. Cabe ressaltar que alguns indivíduos da espécie $L$. tomentosa eram jovens, o que pode ter acarretado a baixa porcentagem de indivíduos em conflito com a rede aérea de transmissão de energia ou de telefonia ou causando danos às calçadas. A espécie C. fistula possui copa que possibilita amenizar as altas temperaturas, possui beleza, principalmente quando em floração, e esteve entre as espécies que apresentaram menor porcentagem de indivíduos em conflito com a rede aérea ou causando danos às calçadas. Todavia, foram amostrados apenas seis indivíduos da chuva-de-ouro. Dentre as espécies citadas, B. aff. purpurea também pode ser uma boa opção para uso na arborização. Os moradores do bairro Centro se mostraram mais satisfeitos com a arborização do seu bairro que os moradores da Vila Isabel (Fig. 1). Isso é um reflexo do número de indivíduos e de espécies encontrados em cada bairro, que foram expressivamente menores na Vila Isabel. No Centro, entre os benefícios que foram citados como os mais importantes estavam os estéticos, o sombreamento e a melhoria da qualidade do ar (Fig. 2), já os aspectos negativos mais citados foram a sujeira causada pelas folhas, os danos às calçadas e os danos à rede aérea de transmissão de energia elétrica (Fig. 3). Na Vila
Isabel, os benefícios mais citados foram a melhoria da qualidade do ar, a melhoria do clima e os benefícios estéticos. Nesse bairro, os aspectos negativos mais citados foram os danos à rede aérea de transmissão de energia elétrica e os danos às calçadas. Ainda sobre o bairro Vila Isabel, 20 pessoas disseram desconhecer problemas causados pela arborização e o mesmo número de moradores manifestaram o seu descontentamento com o baixo número de árvores nesse bairro, embora esse item não constasse na parte aberta do questionário.

A percepção ambiental pode ser conceituada como a consciência do homem sobre o meio que o cerca, o que colabora para a compreensão da importância de se conservar os componentes do ambiente (TRIGUEIRO, 2003). Desse modo, se as pessoas entendem os benefícios advindos das árvores presentes nas calçadas públicas elas podem colaborar para a sua manutenção e cobrar das autoridades os devidos cuidados no seu planejamento e administração. MELO \& PIACENTINI (2011) observaram que a grande maioria das pessoas no município de Colorado-RS conhecem os benefícios da arborização urbana, entretanto também constataram a falta de planejamento e manutenção da arborização no município. RIBEIRO (2009) também observou que a população de Uberlândia-MG compreende que a arborização urbana proporciona benefícios. Com a consciência da população sobre os problemas gerados pela má gestão da arborização urbana esses problemas podem ser minimizados (GRACIOLI et al., 2011). No caso do município de Três Rios, os resultados indicam que boa parte da população percebe os benefícios advindos da arborização e os malefícios causados pela falta de planejamento e de manutenção das árvores. 
Tabela 1. Arborização urbana nos bairros Centro e Vila Isabel, Município de Três Rios-RJ.

\begin{tabular}{|c|c|c|c|c|c|c|c|c|}
\hline Bairro & Espécie & Nome popular & NI & $\operatorname{Fr}(\%)$ & Altura (m) & Copa (m) & CR (\%) & DC $(\%)$ \\
\hline \multirow[t]{24}{*}{ Centro } & Cassia siamea Lam. & Cássia siamea & 34 & 24,46 & $10,41 \pm 3,02$ & $8,12 \pm 2,43$ & 88,89 & 91,18 \\
\hline & Licania tomentosa (Benth.) Fritsch. & Oiti & 24 & 17,27 & $6,68 \pm 4,13$ & $4,58 \pm 2,55$ & 45,45 & 29,17 \\
\hline & Pachira aquatica Aubl. & Munguba & 14 & 10,07 & $8,60 \pm 1,36$ & $6,21 \pm 1,64$ & 100,00 & 92,86 \\
\hline & Terminalia catappa $\mathrm{L}$. & Amendoeira & 12 & 8,63 & $11,06 \pm 4,42$ & $10,39 \pm 2,52$ & 90,00 & 91,67 \\
\hline & Bauhinia aff. purpurea L. & Pata-de-vaca & 12 & 8,63 & $6,53 \pm 2,48$ & $5,81 \pm 2,56$ & 63,63 & 25,00 \\
\hline & Cassia fistula $\mathrm{L}$. & Chuva-de-ouro & 6 & 4,32 & $7,66 \pm 2,90$ & $5,94 \pm 3,35$ & 50,00 & 16,67 \\
\hline & Nerium oleander L. & Espirradeira & 6 & 4,32 & $5,06 \pm 2,91$ & $3,13 \pm 1,54$ & 0,00 & 50,00 \\
\hline & Indeterminada 1 & - & 5 & 3,60 & $3,91 \pm 0,73$ & $3,15 \pm 0,71$ & - & 40,00 \\
\hline & Ligustrum lucidum Ait. & Alfeneiro & 5 & 3,60 & $4,83 \pm 2,07$ & $2,70 \pm 1,08$ & 0,00 & 80,00 \\
\hline & Michelia champaca L. & $\begin{array}{l}\text { Magnólia- } \\
\text { amarela }\end{array}$ & 3 & 2,16 & $5,17 \pm 0,59$ & $2,57 \pm 0,55$ & - & 100,00 \\
\hline & Caesalpinia peltophoroides Benth. & Sibipiruna & 2 & 1,44 & $7,96 \pm 0,69$ & $6,32 \pm 0,73$ & 100,00 & 100,00 \\
\hline & Syzygium malaccense (L.) Merr. \& Perry & Jambo & 2 & 1,44 & $5,55 \pm 4,45$ & $3,60 \pm 0,00$ & - & 50,00 \\
\hline & Tecoma stans (L.) juss. ex H.B.K. & Ipê-de-jardim & 2 & 1,44 & $5,85 \pm 0,72$ & $3,10 \pm 0,14$ & 0,00 & 50,00 \\
\hline & Indeterminada 2 & - & 2 & 1,44 & $4,86 \pm 0,68$ & $3,14 \pm 0,80$ & - & 100,00 \\
\hline & Albizia lebbeck (L.) Benth. & Albizia & 1 & 0,72 & $7,47 \pm 0,00$ & $6,30 \pm 0,00$ & 100,00 & 100,00 \\
\hline & Averrhoa carambola L. & Carambola & 1 & 0,72 & $4,38 \pm 0,00$ & $3,60 \pm 0,00$ & - & 0,00 \\
\hline & Hibiscus rosa-sinensis $\mathrm{L}$. & Hibisco & 1 & 0,72 & $2,50 \pm 0,00$ & $1,55 \pm 0,00$ & - & 100,00 \\
\hline & Lagerstroemia indica Lam. & Extremosa & 1 & 0,72 & $2,60 \pm 0,00$ & $2,00 \pm 0,00$ & - & 0,00 \\
\hline & Malpighia glabra L. & Acerola & 1 & 0,72 & $3,80 \pm 0,00$ & $3,45 \pm 0,00$ & 100,00 & 0,00 \\
\hline & Punica granatum L. & Romã & 1 & 0,72 & $4,38 \pm 0,00$ & $3,90 \pm 0,00$ & 0,00 & 0,00 \\
\hline & Tabebuia sp. & Ipê & 1 & 0,72 & $13,62 \pm 0,00$ & $8,00 \pm 0,00$ & 100,00 & 100,00 \\
\hline & Tibouchina aff. mosenii Cogn. & Quaresminha & 1 & 0,72 & $3,46 \pm 0,00$ & $2,65 \pm 0,00$ & 0,00 & 0,00 \\
\hline & Indeterminada 3 & - & 1 & 0,72 & $10,09 \pm 0,00$ & $7,08 \pm 0,00$ & 100,00 & 100,00 \\
\hline & Indeterminada 4 & - & 1 & 0,72 & $11,70 \pm 0,00$ & $15,40 \pm 0,00$ & 100,00 & 100,00 \\
\hline \multirow[t]{7}{*}{$\begin{array}{l}\text { Vila } \\
\text { Isabel }\end{array}$} & Licania tomentosa (Benth.) Fritsch. & Oiti & 2 & 22,22 & $2,10 \pm 0,14$ & $1,63 \pm 0,04$ & 0,00 & 0,00 \\
\hline & Terminalia catappa L. & Amendoeira & 2 & 22,22 & $6,04 \pm 0,05$ & $4,68 \pm 0,18$ & 100,00 & 100,00 \\
\hline & Albizia lebbeck (L.) Benth. & Albizia & 1 & 11,11 & $1,00 \pm 0,00$ & $0,98 \pm 0,00$ & 0,00 & 0,00 \\
\hline & Caesalpinia peltophoroides Benth. & Sibipiruna & 1 & 11,11 & $4,30 \pm 0,00$ & $3,95 \pm 0,00$ & - & 0,00 \\
\hline & Murraya exotica L. & Murta & 1 & 11,11 & $2,40 \pm 0,00$ & $2,48 \pm 0,00$ & - & 0,00 \\
\hline & Nerium oleander L. & Espirradeira & 1 & 11,11 & $3,60 \pm 0,00$ & $3,25 \pm 0,00$ & 0,00 & 0,00 \\
\hline & Indeterminada 5 & - & 1 & 11,11 & $5,10 \pm 0,00$ & $4,15 \pm 0,00$ & - & 0,00 \\
\hline
\end{tabular}

Nota: NI - número de indivíduos; Fr (\%) - frequência; Altura - altura média; Copa - diâmetro médio da copa; CR - porcentagem de indivíduos em conflito com a rede aérea (elétrica ou de telefonia); DC - porcentagem de indivíduos causando danos às alçadas. 


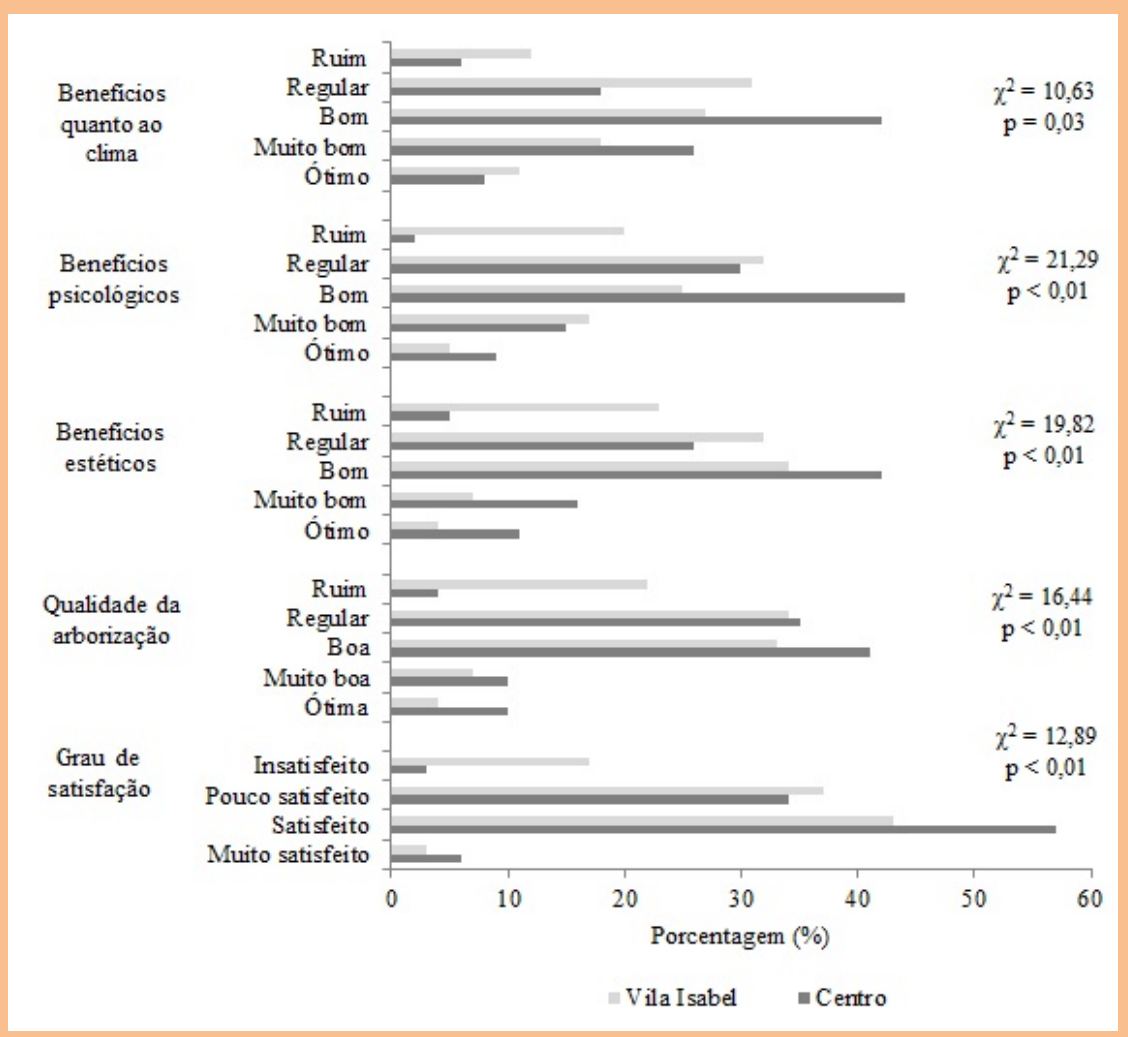

Figura 1. Avaliação da arborização urbana pela população dos bairros Centro e Vila Isabel, Três Rios-RJ.

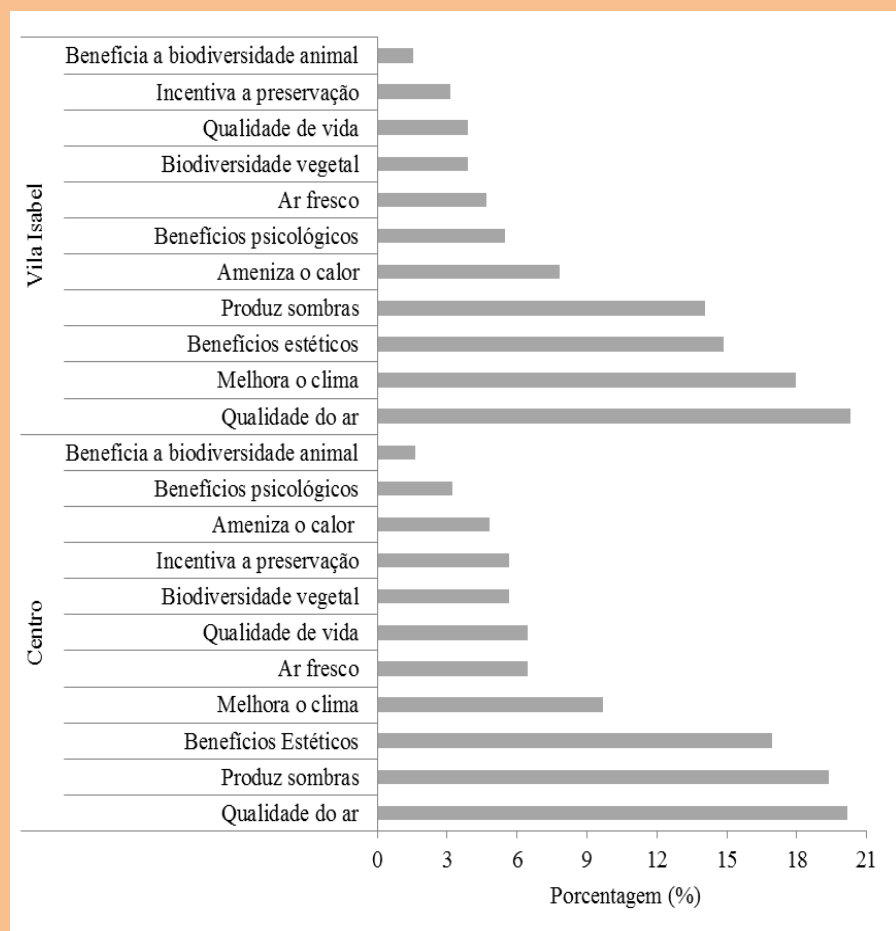

Figura 2. Benefícios da arborização urbana apontados pelos moradores dos bairros Centro e Vila Isabel, Três Rios-RJ.

Débora Chaves Faria et al. 


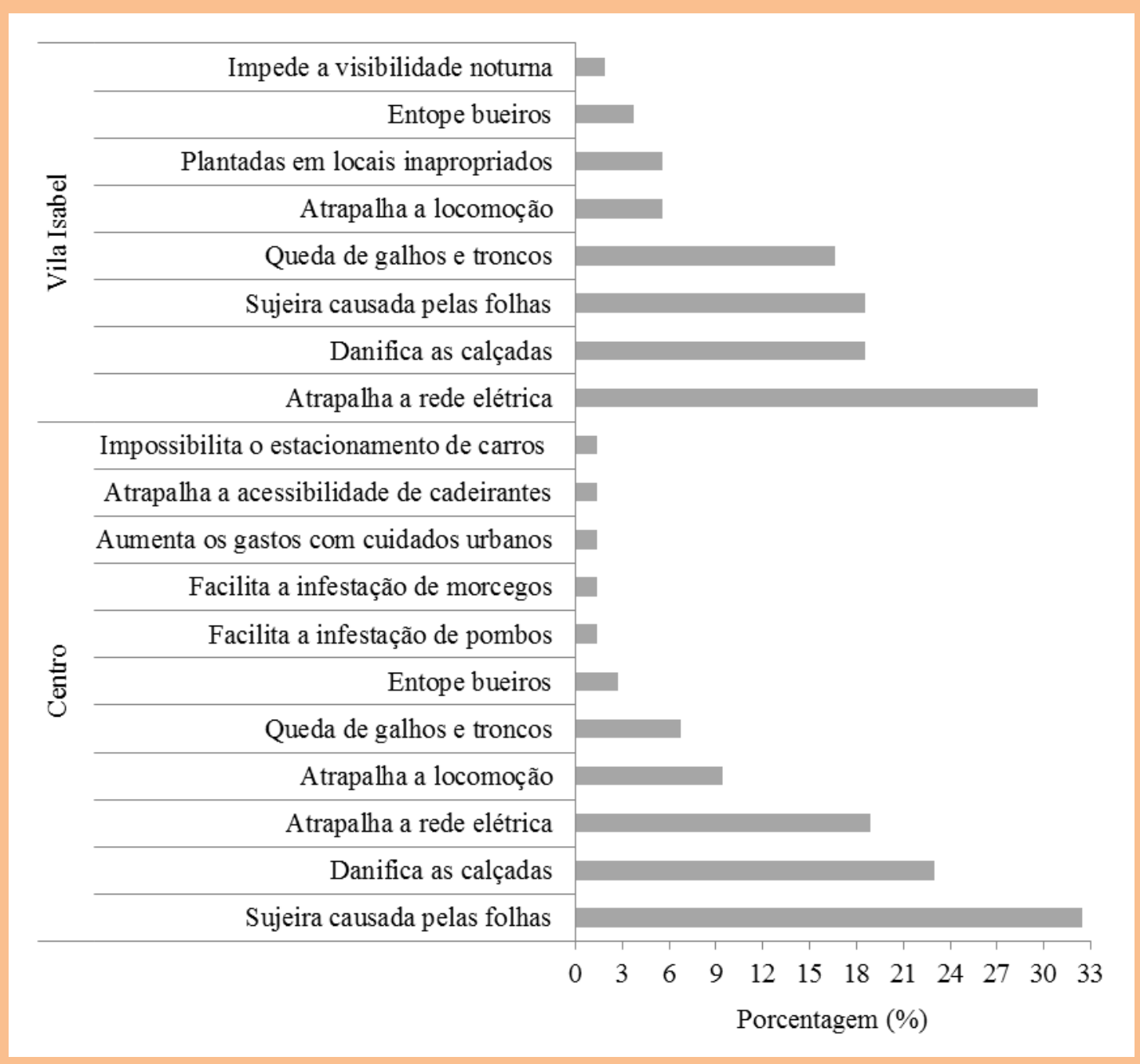

Figura 3. Problemas gerados pela arborização urbana, apontados pelos moradores dos bairros Centro e Vila Isabel, Três Rios-RJ.

\section{CONCLUSÕES}

Dentre as espécies amostradas, as mais promissoras para compor a arborização urbana de Três Rios, devido aos aspectos físicos locais, são $B$. aff. purpurea L. (pata-de-vaca), C. fistula (chuva-deouro), $N$. oleander (espirradeira) e L. tomentosa (oiti).

O bairro Centro é mais arborizado que o bairro Vila Isabel, o que se reflete na avaliação da arborização realizada pelos moradores dos dois bairros. Os moradores do Centro se mostraram mais satisfeitos com a arborização de seu bairro que os moradores da Vila Isabel.

O município de Três Rios necessita da elaboração de um programa que envolva o plantio de novas árvores e a manutenção das árvores já existentes, possibilitando que as pessoas possam usufruir completamente dos benefícios da arborização das vias públicas. 


\section{AGRADECIMENTOS}

Á André Luiz Pereira por ter auxiliado na identificação das espécies.

\section{REFERÊNCIAS BIBLIOGRÁFICAS}

BLUM, C. T.; BORGO, M.; SAMPAIO, A. C. F. Espécies exóticas invasoras na arborização de vias públicas de Maringá-PR. SBAU, v.3, n.2, p.78-97, 2008.

BOHNER, T.; GRACIOLI, C.R.; REDIN, C.G.; SILVA, D.T.; LONGHI, S.J.; ROSA, M.B. Análise qualiquantitativa da arborização do município de Guatambu, SC. Monografias Ambientais, v.3, p.532-546, 2011.

COLTRO, E.M., MIRANDA, G. M. Levantamento da arborização urbana pública de Irati - PR e sua influência na qualidade de vida de seus habitantes. Ano 2, ${ }^{\circ} 1$, julho de 2007. Revista Eletrônica Lato Sensu. Disponível em: <http://www.unicentro.br - Engenharia>. Acesso em: 9 out. 2012.

DANTAS, I. C.; SOUZA, C. M. C.; Arborização urbana na cidade de Campina Grande - PB: inventário e suas espécies. Revista de Biologia e Ciências da Terra, v.4, n.2, 2004.

EMBRAPA - Empresa Brasileira de Pesquisa Agropecuária. Por que manter árvores na área urbana? São Carlos: Embrapa Pecuária Sudeste, 41p. 2009.

FARIA, J. L. G.; MONTEIRO, E. A.; FISCH, S. T. V. Arborização de vias públicas do município de Jacareí-SP. SBAU, v.2, n.4, p. 20-33, 2007.

FERNANDES, A.L.F. Os impactos dos espaços verdes na qualidade do ar. 2007. 63p. Dissertação (Mestrado em Engenharia do Ambiente), Universidade de Aveiro, Oliveira de Azeméis, 2007.

GRACIOLI, C.R.; BOHNER, T.O.L.; REDIN, C.G.; SILVA, D.T. Arborização do campus da Universidade Federal de Santa Maria e conscientização da comunidade acadêmica. Monografias Ambientais, v.3, p.421-429, 2011.

IBGE. Contagem da população 2010. Disponível em: <http://www.ibge.gov.br/ cidade sat/topwindow.htm?1>. Acesso em: 24 out. 2012.

KURIHARA, D. L.; ENCINAS, J. I.; PAULA, J. E. Levantamento da arborização do campus da Universidade de Brasilia. Cerne, v. 11, n. 2, p. 127-136, 2005.

MELO, E.F.R.Q.; PIACENTINI, C.A.M. Diversidade da arborização urbana no Município de Colorado (RS). Ambiência Guarapuava, v.7, p.339-352, 2011.

MILANO, M.S. O planejamento da arborização, as necessidades de manejo e tratamentos culturais das árvores de ruas de Curitiba-PR. Revista Floresta, v.17, n.12, p. 15-21, 1987.

Débora Chaves Faria et al. 
PAIVA, H.N.; Seleção de espécies para arborização urbana. Revista Ação Ambiental, UFV, v.2, n.9, 2000.

PEREIRA, M.C.D.; SANTOS, D.B.; FREITAS FILHO, F.; MELO, M.D. Levantamento florístico do Conjunto dos Professores, Natal/RN: um subsídio para arborização urbana. Carpe Diem: Revista Cultural e Científica do UNIFACEX, v.8, n.8, 2010.

PIVETTA, K.F.L.; SILVA FILHO, D.F.S. Arborização urbana. Boletim Acadêmico - série arborização urbana. UNESP/ FCAV/FUNEP, Jaboticabal, 2002. 69p.

RIBEIRO, F.A.B.S. Arborização urbana em Uberlândia: percepção da população. Revista da Católica, v.1, p.224-237, 2009

ROCHA, R.T.; LELES, P.S.S.; OLIVEIRA NETO, S.N.; Arborização de vias públicas em Nova Iguaçú, RJ: o caso dos bairros Rancho Novo e Centro. Revista Árvore, v.28, p.599-607, 2004.

SANTOS, N.R.Z.; TEIXEIRA, I.F. Arborização de vias públicas: ambiente x vegetação. Santa Cruz do Sul: Instituição Souza Cruz, 2001. 135p.

SMITH, W.H. Removal of atmospheric particulates by urban vegetation: implications for human and vegetative health. The Yale Journal of Biology and Medicine, v.50, p.185-197, 1977.

SPADOTTO, L.G.F.; DELMANTO JÚNIOR, O. Planejamento e gerenciamento da arborização urbana utilizando técnicas de geoprocessamento. Tékhne e Lógos, v.1, p.34-52, 2009.

TEIXEIRA, I.F. Análise quantitativa da arborização de ruas do conjunto habitacional Tancredo Neves, Santa Maria-RS. Ciência Florestal, v.9, p.9-21, 1999.

TRIGUEIRO, A. (Cor.). Meio ambiente no século 21: 21 especialistas falam da questão ambiental nas suas áreas de conhecimento. Rio de Janeiro: Sextante, 2003. 368p.

VELASCO, G.D.N. Arborização viária x sistemas de distribuição de energia elétrica: avaliação dos custos, estudos das podas e levantamento de problemas fitotécnicos. 2003. 94p. Dissertação (Mestrado em Agronomia), Escola Superior e Agricultura “Luiz de Queiroz”, Universidade de São Paulo, Piracicaba, 2003.

ARBORIZAÇÃO URBANA NO MUNICÍPIO DE TRÊS RIOS-RJ... 